\title{
The Pattern of Women's Reliance on Family Planning Providers in Egypt
}

\author{
Hassan H. M. Zaky \\ Department of Psychology, School of Humanities and Social Sciences, and Social Research Center of the American University in \\ Cairo, Cairo, Egypt \\ Email:hzaky@aucegypt.edu
}

How to cite this paper: Zaky, H.H.M. (2020) The Pattern of Women's Reliance on Family Planning Providers in Egypt. $A d$ vances in Reproductive Sciences, 8, 82-95. https://doi.org/10.4236/arsci.2020.81008

Received: January 25, 2020

Accepted: February 23, 2020

Published: February 26, 2020

Copyright (c) 2020 by author(s) and Scientific Research Publishing Inc. This work is licensed under the Creative Commons Attribution International License (CC BY 4.0).

http://creativecommons.org/licenses/by/4.0/

\begin{abstract}
Understanding choice of family planning provider is fundamental for policy makers and program managers as they seek ways to both improve the coverage and increase the sustainability and efficiency of family planning services for Egypt to achieve its population objectives. This study focuses first on providing a descriptive profile of the patterns of reliance on sources of family planning services during the early 2000s. Binomial logit models are then estimated to obtain a more in depth understanding of the determinants of the choice of family planning providers in Egypt using the 2000 Egypt Demographic and Health Survey. The study offers insights into a number of aspects of family planning service provision about which there has been less previous investigation. There are marked differences in the extent to which Egyptian women rely on public or private providers for family planning services depending on the type of method they are seeking. Among the more important findings is the consistency women display in the choice of provider among women reporting multiple segments of use. With regard to the determinants of the choice of provider for family planning services, perhaps the most interesting finding is that household wealth was not a significant determinant of the choice of provider. This may reflect that private sources met the demand for family planning services of significant proportions of women in rural areas and among those in the low income groups.
\end{abstract}

\section{Keywords}

Choice of Family Planning Providers, Women's Reliance, Determinants, Egypt

\section{Introduction}

There is growing appreciation that women who obtain contraceptive services 
often have other reproductive health care needs, and that women obtaining other reproductive health care may have unmet contraceptive needs and that the needs of both of these groups of women can often be met best by providers who are able to offer a range of services. An inadequate supply of reproductive health preventive and curative services is thought to be an important factor contributing to women's poor health status and high maternal mortality rates in developing countries.

Ideally, the availability of reproductive health services should not be a constraint to accessing reproductive health care. Beyond basic availability, other issues relating to supply become important including the factors that affect provider choice in cases where multiple outlets offering the same or similar services co-exist. In looking at provider choice, a common dichotomy is between public and private providers. Where public and private sector outlets offer the same services, they generally differ in terms of price, convenience, etc., leading the user to select an outlet on the basis of income, opportunity costs and personal preferences. In some instances, the public sector may distort the market by extending subsidies to clients willing and be able to pay higher prices for goods and services. Usually research about providers mainly focuses on the supply side such as training of providers [1], knowledge and practices [2], nature of visit [3], provider characteristics [4], the "culture" of service delivery [5], communication with clients [6], and integration of services [7]. On the other side, the demand in many instances is overlooked [8].

In Egypt during the early years of the $21^{\text {st }}$ century, contraceptive and other reproductive health care services were offered by almost 5000 public health care unit, and more than 20,000 private-practice obstetrician-gynecologists, and other sources (such as private clinics, hospital, mosques/churches, NGOs, etc.). Despite of this medical network, which is almost equivalent to that in some developed countries, Egypt contraceptive prevalence rate reached only 56 percent in 2000 with 54 percent depending on modern methods and a total fertility rate of 3.5 live births/woman [9]. Unmet need for contraception reached 11 percent while discontinuation rate was as high as 30 percent within 12 months of starting use. Egypt's population policy at that time was to reach fertility replacement level by the year 2017. This required increasing prevalence, to almost 75 percent, decreasing discontinuation rate and unmet need, plus other reforms on other dimensions, such as the improvement of female education status, which were beyond the scope of this study. Being now in 2020, Egypt was not able to achieve this fertility objective and even changed the whole population policy and its objectives.

This article attempts to obtain more detailed insight into the factors that influenced the choice of provider for family planning in Egypt during 2000. An understanding of the historical patterns of provider choice and their determinants will be of use to policy makers and program managers as they seek ways in which to both improve the coverage and increase the sustainability and efficien- 
cy of family planning services for Egypt to achieve its population objectives. While the need for such investigation has been recognized, research relating to the choice of family planning provider in Egypt is limited. Literature addressing aspects of the issue within the Egyptian context includes few efforts [10].

This article has two purposes: to describe historical patterns of reliance on public and private providers among family planning users; and to identify the determinants of the choice of public and private providers in 2000.

\section{Data}

The data on the sources from which women obtained family planning services used in this article was drawn from information collected in Egypt Demographic and Health Survey (EDHS) conducted in the year 2000, which also included a detailed description of the sample. In the 2000 EDHS, family planning source information was collected for all episodes of contraceptive use during the five-year period before the survey. With regard to the current segment of use, information was obtained from all users on the source from which the method was obtained at the beginning of the current segment of use and, for users of methods requiring periodic resuppply (pills, injectables, condoms and vaginal methods), on the source to which user had gone most recently to obtain the method. For episodes other than the current segment, the source was the outlet at which the method was obtained at the beginning of the segment. For purposes of the analysis that followed, the family planning source was generally grouped by sector (public or private). In looking at the sources for methods requiring resupply (e.g., the pill), the source was also looked at from the point of view of the type of provider (clinical and pharmacy/nonclinical).

\subsection{Source at Beginning of Current Segment of Use}

Intrauterine contraceptive Device (IUD) was the most common method in Egypt since it was being used by almost 66 percent of current users. Pill was the second method (almost 18 percent). Table 1 shows the distribution of current users of modern methods by type of source from which the method was obtained at the beginning of the current segment of use. Overall, at the time they began using their method, one in every two of these users went to a public sector source for the method, one-third obtained the method from a private clinic (including private hospital/clinic/doctors, NGO/PVO clinics, and mosque/church clinics), and 11 percent went to pharmacies. The source from which users obtained services at the beginning of the current segment varied markedly by method. Table 1 shows that the majority of IUD insertions occurred at a public sector source (54 percent) while 40 percent of the insertions were performed at private clinics. Four out of five users obtained the injectable at a public sector source at the beginning of the current segment of use, and almost all Norplant insertions took place at public facilities. The comparatively few respondents who reported use of female sterilization were evenly split between those obtaining the 
method at a public sector provider and those relying on a private provider.

At the beginning of the current segment, pill, condom and vaginal method users were more likely to report getting the method at a pharmacy (53 percent, 66 percent, and 46 percent respectively) than from either public or private clinical provider. Figure 1 compares the source at the beginning of the current segment with the source where the last supply of the method was obtained for current users of the pill and condoms. The results indicate that, as expected, many of the users who obtained these methods from a clinical provider switched to a pharmacy for resuppply.

\subsection{Differentials in Family Planning Sources by Background Characteristics}

Table 2 and Table 3 present the distributions of current users by the type of source at the beginning of the segment according to selected demographic and

Table 1. Percent distribution of users of modern methods by type of source from which the method was obtained at the beginning of the current segment of use according to the method used, Egypt DHS 2000.

\begin{tabular}{ccccccccc}
\hline Type of source & Pill & Condom & IUD & Injectables & Nor-plant & $\begin{array}{c}\text { Female } \\
\text { sterilization }\end{array}$ & $\begin{array}{c}\text { Vaginal } \\
\text { methods }\end{array}$ & $\begin{array}{c}\text { All } \\
\text { modern } \\
\text { methods }\end{array}$ \\
\hline Public & 18.3 & 16.9 & 54.0 & 80.0 & 95.2 & 46.5 & 13.0 & 49.8 \\
NGO/PVO & 0.7 & 1.7 & 6.9 & 2.8 & 0.0 & 1.5 & 0.0 & 5.1 \\
Private clinical & 27.6 & 11.8 & 39.1 & 14.7 & 4.8 & 51.9 & 40.5 & 34.1 \\
Pharmacy & 53.1 & 65.9 & 0.0 & 2.0 & 0.0 & 0.0 & 46.5 & 10.9 \\
Other** & 0.3 & 3.7 & 0.0 & 0.6 & 0.0 & 0.0 & 0.0 & 0.2 \\
Total percent & 100.0 & 100.0 & 100.0 & 100.0 & 100.0 & 100.0 & 100.0 & 100.0 \\
Number of users & 1362 & 140 & 5112 & 876 & 32 & 217 & 23 & 7760 \\
\hline
\end{tabular}

IUD = intrauterine contraceptive device; $\mathrm{NGO}=$ non-governmental organization; $\mathrm{PVO}=$ private voluntary organization; ${ }^{\star}$ Includes private hospital/clinic/doctor and mosques/church clinic; ${ }^{* \star}$ Includes friends/relatives and other.

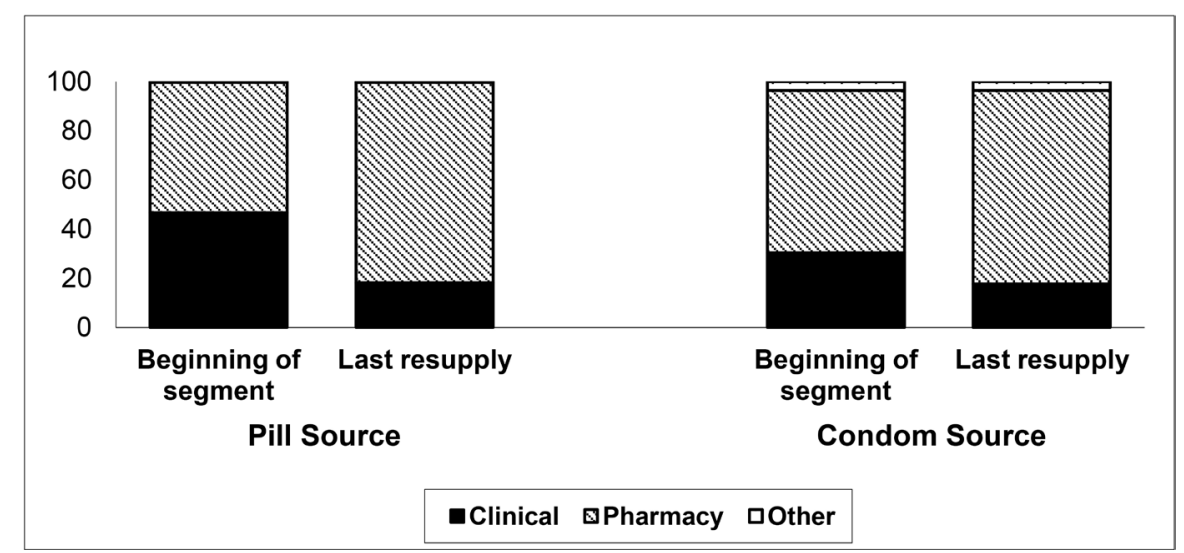

Figure 1. Type of source at beginning of current segment of use and at last resupply by method. 
Table 2. Percent distribution of users of the IUD by the type of source at the beginning of the segment according to selected background characteristics, Egypt DHS 2000.

\begin{tabular}{|c|c|c|c|c|c|}
\hline \multirow{2}{*}{ Characteristics } & \multicolumn{3}{|c|}{$\begin{array}{l}\text { Source of method at the } \\
\text { beginning of segment }\end{array}$} & \multirow{2}{*}{ Total } & \multirow{2}{*}{$\begin{array}{l}\text { Numbe } \\
\text { of users }\end{array}$} \\
\hline & Public & NGO/PVO & $\begin{array}{l}\text { Private } \\
\text { clinical }\end{array}$ & & \\
\hline \multicolumn{6}{|l|}{ Age } \\
\hline $15-24$ & 59.4 & 6.4 & 34.2 & 100.0 & 738 \\
\hline $25-39$ & 54.2 & 7.2 & 38.6 & 100.0 & 3222 \\
\hline $40-49$ & 49.8 & 6.5 & 43.6 & 100.0 & 1152 \\
\hline \multicolumn{6}{|l|}{ Type of place of residence } \\
\hline Urban & 48.7 & 6.6 & 44.7 & 100.0 & 2593 \\
\hline Rural & 59.4 & 7.2 & 33.3 & 100.0 & 2518 \\
\hline \multicolumn{6}{|l|}{ Region } \\
\hline Urban Governorates & 48.8 & 4.3 & 46.9 & 100.0 & 1218 \\
\hline Lower Egypt & 54.9 & 8.0 & 37.1 & 100.0 & 2584 \\
\hline Urban & 47.5 & 10.4 & 42.0 & 100.0 & 755 \\
\hline Rural & 58.0 & 7.0 & 35.0 & 100.0 & 1829 \\
\hline Upper Egypt & 57.3 & 7.2 & 35.6 & 100.0 & 1271 \\
\hline Urban & 50.1 & 6.4 & 43.4 & 100.0 & 593 \\
\hline Rural & 63.5 & 7.8 & 28.7 & 100.0 & 678 \\
\hline Frontier Governorates & 44.9 & 12.1 & 43.0 & 100.0 & 38 \\
\hline \multicolumn{6}{|l|}{ Education } \\
\hline No Education & 62.6 & 6.1 & 31.4 & 100.0 & 1795 \\
\hline Primary Incomplete & 61.8 & 6.8 & 31.4 & 100.0 & 629 \\
\hline Primary complete, some secondary & 57.5 & 6.3 & 36.3 & 100.0 & 678 \\
\hline Secondary Complete, higher & 42.7 & 8.0 & 49.4 & 100.0 & 2009 \\
\hline \multicolumn{6}{|l|}{ Wealth Index Quintiles } \\
\hline 1 & 67.0 & 4.7 & 28.3 & 100.0 & 655 \\
\hline 2 & 64.8 & 6.8 & 28.5 & 100.0 & 804 \\
\hline 3 & 60.8 & 6.7 & 32.5 & 100.0 & 811 \\
\hline 4 & 58.2 & 7.3 & 34.5 & 100.0 & 983 \\
\hline 5 & 39.5 & 7.7 & 52.8 & 100.0 & 1858 \\
\hline \multicolumn{6}{|l|}{ Working for cash } \\
\hline Currently working for cash & 46.6 & 9.6 & 43.8 & 100.0 & 917 \\
\hline Not working for cash & 55.6 & 6.4 & 38.1 & 100.0 & 4195 \\
\hline \multicolumn{6}{|l|}{ Partner's Occupation } \\
\hline Professional/Technical/Managerial & 41.2 & 7.8 & 51.0 & 100.0 & 1500 \\
\hline Other/Not working & 59.2 & 6.6 & 34.2 & 100.0 & 3612 \\
\hline
\end{tabular}


Continued

\begin{tabular}{cccccc}
\hline Number of living children & & & & & \\
$0-3$ & 51.9 & 7.4 & 40.7 & 100.0 & 3280 \\
$4+$ & 57.6 & 6.2 & 36.1 & 100.0 & 1832 \\
Desire for more & & & & & \\
Wants no more & 53.1 & 6.7 & 40.1 & 100.0 & 3984 \\
Wants more/Unsure & 56.8 & 7.6 & 35.5 & 100.0 & 1128 \\
Total & 54.0 & 6.9 & 39.1 & 100.0 & 5112 \\
\hline
\end{tabular}

socio-economic characteristics for the IUD and pill users-the two most popular methods in Egypt. The tables offer insights into how patterns of reliance on public and private sector providers varied among users of these methods. In the case of pill users, the results also permitted an exploration of the question of how users who consulted a clinical provider when they began using the method differed from users who got the method from a pharmacy without consulting a clinical provider.

For IUD users, the tendency to go to public sector sources decreased and reliance on private clinics increased somewhat in importance as the respondent got older. For instance, 59 percent of IUD users 15 - 24 obtained the method from public sources compared to around 50 percent of those 40 - 49 years. In the case of the pill, in contrast, age was not strongly related to whether a user went to a clinical source or the pharmacy at the beginning of a segment of use. In addition, among pill users who obtained the method from a clinical source, age differentials in the likelihood of going to a public or private outlet are not marked.

Urban-rural residence and place of residence were clearly related to the type of source from which women sought contraceptive services. Rural users were more likely to get the IUD from a public source than urban women. For example, 59 percent of current IUD users in rural areas got the method from a public source compared to 49 percent of urban IUD users (Table 2). Rural users were somewhat more likely than urban users to get the pill from pharmacies without consulting a clinical source. Moreover, urban users who got the pill from a clinical source were much more likely to obtain it at private than at public outlets while rural pill users were more evenly divided between using public and private clinics (Table 3).

Looking at the differentials by place of residence, reliance on public sources for the IUD was most common in rural Upper Egypt, followed by rural Lower Egypt. Interestingly, there was somewhat greater variability in the level of reliance of IUD users on NGO/PVO providers by place of residence than existed for other characteristics. Pill users were least likely to get the method from a pharmacy at the beginning of the segment of use in urban Upper Egypt (46 percent) and most likely to get it there in rural Lower Egypt (57 percent). Among urban pill users who did seek services from a clinical provider, private outlets were markedly more popular than public outlets, whether the user lived in the Urban 
Table 3. Percent distribution of users of the pill by the type of source at the beginning of the segment according to selected background characteristics, Egypt DHS 2000.

\begin{tabular}{|c|c|c|c|c|c|c|c|}
\hline \multirow{2}{*}{ Characteristics } & \multicolumn{5}{|c|}{ Source of method at the beginning of segment } & \multirow{2}{*}{ Total } & \multirow{2}{*}{$\begin{array}{l}\text { Numbe } \\
\text { of users }\end{array}$} \\
\hline & Public & NGO/PVO & $\begin{array}{l}\text { Private } \\
\text { clinical }\end{array}$ & Pharmacy & Other & & \\
\hline \multicolumn{8}{|l|}{ Age } \\
\hline $15-24$ & 19.3 & 0.2 & 30.0 & 50.3 & 0.2 & 100.0 & 171 \\
\hline $25-39$ & 18.6 & 0.6 & 26.7 & 53.6 & 0.5 & 100.0 & 855 \\
\hline $40-49$ & 16.9 & 1.2 & 28.6 & 53.2 & 0.0 & 100.0 & 336 \\
\hline \multicolumn{8}{|l|}{ Type of place of residence } \\
\hline Urban & 14.5 & 0.8 & 33.8 & 50.6 & 0.4 & 100.0 & 654 \\
\hline Rural & 21.7 & 0.7 & 21.9 & 55.5 & 0.2 & 100.0 & 707 \\
\hline \multicolumn{8}{|l|}{ Region } \\
\hline Urban Governorates & 15.2 & 0.8 & 33.4 & 49.5 & 1.1 & 100.0 & 223 \\
\hline Lower Egypt & 19.3 & 0.4 & 24.0 & 56.4 & 0.0 & 100.0 & 645 \\
\hline Urban & 13.1 & 0.6 & 31.1 & 55.1 & 0.0 & 100.0 & 227 \\
\hline Rural & 22.6 & 0.3 & 20.1 & 57.1 & 0.0 & 100.0 & 419 \\
\hline Upper Egypt & 18.0 & 1.0 & 30.5 & 50.2 & 0.4 & 100.0 & 469 \\
\hline Urban & 15.0 & 0.6 & 38.6 & 45.8 & 0.0 & 100.0 & 188 \\
\hline Rural & 20.0 & 1.3 & 25.0 & 53.1 & 0.6 & 100.0 & 281 \\
\hline Frontier Governorates & 24.9 & 2.9 & 16.0 & 56.2 & 0.0 & 100.0 & 25 \\
\hline \multicolumn{8}{|l|}{ Education } \\
\hline No Education & 18.4 & 0.4 & 21.8 & 58.7 & 0.7 & 100.0 & 543 \\
\hline Primary Incomplete & 19.6 & 0.5 & 24.8 & 55.2 & 0.0 & 100.0 & 191 \\
\hline Primary complete, some secondary & 16.9 & 2.1 & 32.5 & 48.5 & 0.0 & 100.0 & 222 \\
\hline Secondary Complete, higher & 18.1 & 0.5 & 34.0 & 47.2 & 0.1 & 100.0 & 406 \\
\hline \multicolumn{8}{|l|}{ Wealth Index Quintiles } \\
\hline 1 & 26.5 & 0.0 & 12.6 & 60.6 & 0.3 & 100.0 & 177 \\
\hline 2 & 19.1 & 0.2 & 16.3 & 64.0 & 0.4 & 100.0 & 192 \\
\hline 3 & 21.7 & 1.3 & 24.1 & 52.3 & 0.6 & 100.0 & 278 \\
\hline 4 & 19.1 & 0.8 & 28.5 & 51.3 & 0.4 & 100.0 & 301 \\
\hline 5 & 11.4 & 0.8 & 41.0 & 46.7 & 0.1 & 100.0 & 414 \\
\hline \multicolumn{8}{|l|}{ Working for cash } \\
\hline Currently working for cash & 18.3 & 1.6 & 28.0 & 52.1 & 0.0 & 100.0 & 189 \\
\hline Not working for cash & 18.3 & 0.6 & 27.5 & 53.3 & 0.4 & 100.0 & 1173 \\
\hline \multicolumn{8}{|l|}{ Partner's Occupation } \\
\hline Professional./Technical/Managerial & 16.9 & 1.0 & 37.4 & 44.8 & 0.0 & 100.0 & 328 \\
\hline Other/Not working & 18.7 & 0.6 & 24.5 & 55.8 & 0.4 & 100.0 & 1034 \\
\hline
\end{tabular}




\section{Continued}

Number of living children

$\begin{array}{lccccccc}0-3 & 17.4 & 0.5 & 30.8 & 50.8 & 0.3 & 100.0 & 728 \\ 4+ & 19.2 & 0.9 & 23.9 & 55.7 & 0.3 & 100.0 & 634 \\ \text { re for more } & & & & & & & \\ \text { ts no more } & 17.6 & 0.9 & 27.1 & 54.1 & 0.3 & 100.0 & 1088 \\ \text { more/Unsure } & 20.7 & 0.1 & 29.6 & 49.1 & 0.5 & 100.0 & 274 \\ \text { Total } & 18.3 & 0.7 & 27.6 & 53.1 & 0.3 & 100.0 & 1362\end{array}$

Governorates, urban Lower Egypt, or urban Upper Egypt. In contrast, among rural pill users who obtained the method from a clinical provider, the division between private and public outlets is more balanced.

A respondent's education and work status, her husband's occupation and the household's position on the wealth index tended to markedly affect the choice of the source among IUD users. Users of these methods who were more educated, working for cash, married to men in professional, technical or managerial occupations, and/or living in a household at the top of the wealth index were less inclined to obtain the method from public sources and more inclined to rely on private clinics than other users.

Among pill users, these characteristics also were associated with the type of source, particularly with the likelihood of consulting at a clinic rather than getting the method from a pharmacy. For example, among users at the bottom of the wealth index, 61 percent got the method from pharmacies at the beginning of the current segment of use. In contrast, among users from households at the other end of the household wealth scale, around 41 percent consulted a clinical provider at the beginning of the segment.

Regarding injectables which was the third most common family planning method in Egypt (11 percent), the reliance on public providers was very clear regardless of background characteristics of users. However, reliance on private providers increased with age, education, and wealth of users, and among urban residents (table not shown).

Finally, despite the close association between the user's socio-economic level and the likelihood of reliance on a private clinical provider for contraceptive services, the findings also indicated that many users belonging to relatively wealthy households obtained services from public providers. For example, 40 percent of the current IUD users living in households ranked at the top of the household wealth index obtained the method from a public provider.

\subsection{Consistency in Choice of Sources}

The 2000 EDHS collected information on the source from which a user obtained the method for all segments of use of family planning methods during the five-year period before the survey. These data were used to answer questions about whether family planning users tended to remain "loyal" to a particular 
type of source in accessing services or whether they "switched" public and private sources for services. Since injectables were for the most part only obtained from public sources, the analysis of patterns of consistency was limited to IUD and pill users who reported two or segments of use of the method during the five-year period before the survey.

Regarding consistency of type of provider among IUD users, Table 4 shows the percent distribution of women reporting multiple segments of IUD use during the five-year period prior to the survey by type of source from which method was obtained during the segments of use according to the number of segments of use. The results clearly suggest there was a high degree of consistency in the type of provider. Four in five of the women who reported multiple segments of IUD use relied on the same type of provider across all of the segments of use. Forty-five percent were consistent in the choice of a public provider, 31 percent always went to private source, while 5 percent consistently got the IUD from a NGO/PVO clinic.

Table 5 indicates that, like IUD users, pill users tended to be consistent in

Table 4. Percent distribution of IUD users reporting multiple segments of use during the five-year period prior to the survey by the type of source from which method was obtained during the segments of use according to the number of segments of use, Egypt DHS 2000.

\begin{tabular}{cccc}
\hline Source & Two & Three & $\begin{array}{c}\text { Total reporting multiple } \\
\text { segments of IUD use }\end{array}$ \\
\hline Always same type & 81.3 & 69.6 & 81.0 \\
Public & 45.0 & 33.4 & 44.7 \\
NGO/PVO & 5.3 & 5.3 & 5.3 \\
Private & 31.0 & 30.9 & 31.0 \\
Different types of sources & 18.7 & 30.4 & 19.0 \\
Total Percent & 100.0 & 100.0 & 100.0 \\
Number of women & 776 & 20 & 797 \\
\hline
\end{tabular}

IUD = intrauterine contraceptive device; $\mathrm{NGO}=$ non-governmental organization; $\mathrm{PVO}=$ private voluntary organization; Note: Private includes private doctor/clinic and mosque/church clinic.

Table 5. Percent distribution of pill users reporting multiple segments of use during the five-year period by consistency in the kind of provider (clinical versus pharmacy/other) from which the pill was obtained according to the number of segments of use, Egypt DHS 2000.

\begin{tabular}{ccccc}
\hline Source & Two & Three & Four/more & $\begin{array}{c}\text { Total reporting multiple } \\
\text { segments of pill use }\end{array}$ \\
\hline Always same type & 79.3 & 80.2 & 94.6 & 80.3 \\
Always clinical source & 25.3 & 20.5 & 27.8 & 24.7 \\
Always pharmacy & 54.0 & 59.7 & 66.8 & 55.6 \\
Clinical and pharmacy & 20.4 & 19.8 & 5.4 & 19.7 \\
Total Percent & 100.0 & 100.0 & 100.0 & 100.0 \\
Number of users & 274 & 58 & 18 & 350 \\
\hline
\end{tabular}


the choice of provider across multiple segments of use. Only around 20 percent of pill users switched between a clinical source and the pharmacy. More than half pill users consistently got their method from the pharmacy, and one woman in every four obtained it from clinical sources. Among those pill users who consulted clinical sources, this group of women also tended to be consistent in the choice of the type of clinical provider. 91 percent were consistent while only 9 percent used different types of providers. Among consistent users, 80 percent always used private sources while 11 percent relied on public sources.

\section{Effect of Women's Characteristics on Choice of Family Planning Providers}

Studies of the demand for health care examined the effect of various provider characteristics on consumers' choice of provider for general medical care. In the family planning literature, estimation of the effects of quality characteristics of providers on choice of provider has been attempted [4]. The focus has always been the provider's characteristics. The users' or consumers' perspective is usually treated as a side issue. This article attempts here to further examine the determinants of the type of provider on which Egyptian women relied. The basic model used for exploring this question is a standard utility maximizing model which assumes that choice of provider is a function of the age of individual client, her educational status, work status, husband's occupation, number of living children, region of residence, household wealth, and type of method. The binomial logit model is used and the odds ratios are estimated.

Several model specifications are tested. Model 1 includes all users of the pill, IUD, and injectables who obtained their method from either a public sector provider or from a private doctor/clinic; users getting the method from other types of sources are excluded from the analysis. Model 2 is limited to users who also had a birth in the five-year period before the survey. In addition to the basic socio-demographic variables, a variable on the use of antenatal care services is introduced into this model. Model 3, which is limited to users who had a birth and obtained antenatal care services, includes a variable on the type of provider from which the antenatal care for the last birth was obtained.

The results of Model 1 indicate that the older the woman is the higher her odds to choose private family planning providers. Older women (40 - 49) have double the odds to go to private sources compared to younger women (15 - 24). IUD and Injectables users had at least thirteen times the odds for choosing a public source than pill users have. Increased education was associated with reliance on private provider. Somewhat surprisingly, employed women were more likely to go to public providers. Probably this result was due to that employed women mainly work in the public sector which was linked to a public health care and health insurance systems. Women married to men working in manageri$\mathrm{al} /$ technical/professional jobs were more likely to get their contraceptive me- 
thods from private providers than others. Rural Upper Egypt residents tended to go to public sector providers. Surprisingly, household wealth was not significantly associated with the type of provider from which the user obtained her method.

The addition of use of antenatal care in the second model provides some additional insight into the patterns of provider choice. Users who had given birth in the five-year period and received antenatal care were significantly more likely to have obtained a method from a private provider. It is worth noting that age was no longer important in determining type of provider which may be related to the fact that older users who had a recent child were a select subset of all users in those age groups. Confining the analysis to those who received antenatal care (Model 3), the consistency of provider choice was clear; women going to public providers for antenatal care tended to go to public providers for their family planning method, almost four times the odd of going to a private provider.

The study considers two more subsets of users, namely IUD and pill users. For IUD users, the results paralleled the findings for all users in Table 6. Older and more educated IUD users and those married to men in managerial/technical/ professional occupations were more likely to obtain the method from private providers. Employed women were more likely to go to public providers. Rural Upper Egypt users were more likely to rely on public sources. Wealth apparently had no bearing on women's choice of one type of provider over the other.

With respect to the pill, the tested model considered the determinants of the likelihood of getting the method from the pharmacy at the pharmacy versus a clinical provider. None of the variables were significantly related to type of provider with the exception of residence in rural Lower Egypt where users had lower odds to getting the pill from pharmacy. It was hypothesized that the lack of fit for other determinants might be due to the very high prevalence use of pharmacy since 84 percent of users obtain the pill at a pharmacy. However, when a model was run in which the group of pill users was limited to those who consulted a clinical source at the beginning of the segment of use, none the socioeconomic determinants of interest were related to the type of clinical provider (not shown in table).

\section{Concluding Remarks and Policy Implications}

A number of conclusions can be drawn from this examination of family planning providers in the early 2000s. First of all, the study confirmed the fact that there were marked differences in the extent to which Egyptian women relied on public or private providers for family planning services depending on the type of method they were seeking. This is perhaps most clearly illustrated in the well-known association between the type of method used and the source from which women seek contraceptive services. Pharmacies supplied the vast majority of pill users, public facilities served the vast majority of injectable users while IUD users were more equally divided between those seeking services from public 
Table 6. Odds ratios of binomial logit models for choice of type of family planning provider.

\begin{tabular}{|c|c|c|c|}
\hline \multirow{2}{*}{ Explanatory Variables } & \multicolumn{3}{|c|}{$\begin{array}{l}\text { Dependent Variable: Type of family planning provider } \\
\qquad(\text { Private }=0 ; \text { Public }=1)\end{array}$} \\
\hline & Model 1 & Model 2 & Model 3 \\
\hline \multicolumn{4}{|l|}{ Age } \\
\hline $15-24$ & $\mathrm{Rc}$ & $\mathrm{Rc}$ & Rc \\
\hline $25-39$ & $0.854^{*}$ & 0.954 & 0.915 \\
\hline $40-49$ & $0.591^{* * *}$ & 0.764 & 0.573 \\
\hline \multicolumn{4}{|l|}{ Number of living children } \\
\hline 0 - 3 children & Rc & Rc & $\mathrm{Rc}$ \\
\hline 4 or more children & 1.108 & 0.970 & 1.047 \\
\hline \multicolumn{4}{|l|}{ Type of contraceptive method } \\
\hline Pill & Rc & $\mathrm{Rc}$ & $\mathrm{Rc}$ \\
\hline IUD & $13.475^{\star \star \star}$ & $13.417^{* * *}$ & $10.493^{* * *}$ \\
\hline Injectables & $43.118^{* * *}$ & $42.857^{* * *}$ & $31.019^{* * *}$ \\
\hline \multicolumn{4}{|l|}{ Region } \\
\hline Urban Governorates & Rc & $\mathrm{Rc}$ & Rc \\
\hline Urban Lower Egypt & 1.017 & 1.096 & $1.158^{*}$ \\
\hline Rural Lower Egypt & 1.099 & $1.257^{\star}$ & 1.272 \\
\hline Urban Upper Egypt & 1.011 & 1.101 & 1.059 \\
\hline Upper Egypt Rural & $1.297^{* *}$ & $1.453^{* * *}$ & $1.367^{\star}$ \\
\hline Frontier Governorates & 1.144 & 1.169 & 0.954 \\
\hline \multicolumn{4}{|l|}{ Education } \\
\hline No education & Rc & Rc & $\mathrm{Rc}$ \\
\hline Primary complete & 1.061 & $1.267^{\star *}$ & 1.259 \\
\hline Primary complete/some secondary & $0.640^{* * *}$ & $0.757^{* * *}$ & $0.758^{\star *}$ \\
\hline Secondary/higher & $0.268^{* * *}$ & $0.360^{* * *}$ & $0.415^{\star * *}$ \\
\hline \multicolumn{4}{|l|}{ Women's work status } \\
\hline Not working for cash & Rc & $\mathrm{Rc}$ & Rc \\
\hline Working for cash & $1.325^{* * *}$ & $1.332^{* * *}$ & $1.356^{* *}$ \\
\hline \multicolumn{4}{|l|}{ Husband's occupation } \\
\hline Other/Not working & Rc & $\mathrm{Rc}$ & $\mathrm{Rc}$ \\
\hline Professional/technical/managerial & $0.695^{* * *}$ & $0.715^{* * *}$ & $0.698^{* * *}$ \\
\hline \multicolumn{4}{|l|}{ Household wealth index score } \\
\hline 1 & Rc & Rc & $\mathrm{Rc}$ \\
\hline $2-4$ & 1.001 & 1.059 & 1.136 \\
\hline 5 & 0.847 & 0.956 & 1.020 \\
\hline
\end{tabular}




\begin{tabular}{cccc}
\hline $\begin{array}{c}\text { Antenatal care } \\
\text { No }\end{array}$ & $\mathrm{Rc}$ & $\mathrm{Rc}$ & $\mathrm{Rc}$ \\
Yes & & $0.691^{* * *}$ & \\
Antenatal care provider & & & \\
Private & $\mathrm{Rc}$ & $\mathrm{Rc}$ & $\mathrm{Rc}$ \\
Public & & & $4.374^{* * *}$ \\
Constant & $0.176^{* * *}$ & $0.166^{* * *}$ & $0.098^{* * *}$ \\
$\mathrm{~N}$ (number of women) & 6647 & 4063 & 2336 \\
Df & 17 & 18 & 18 \\
-2 Log Likelihood & 7340.010 & 4401.632 & 2544.701 \\
\hline Rc $=$ reference category for the variable. ${ }^{* * *} \mathrm{p}<0.01 ;{ }^{* *} 0.01<\mathrm{p}<0.05 ; * 0.05<\mathrm{p}<0.10$. &
\end{tabular}

sector providers and those obtaining the method from private providers.

The study offered insights into a number of other aspects of family planning service provision about which there had been less previous investigation. Among the more important findings was the consistency women displayed in the choice of provider. The majority of women reported multiple segments of use of the same family planning in the five-year period before the survey reported obtaining the method from the same type of source at each segment of use.

With regard to the determinants of the choice of provider for family planning services, perhaps the most interesting finding was that household wealth was not a significant determinant of the choice of provider. This may reflect that private sources met the demand for family planning services of significant proportions of women in rural areas and among those in the low income groups. Also, significant numbers among those in the high income groups were almost paying nothing to get their methods. This finding had significant policy implications since it suggested that public subsidies were not reaching those in need the most. More in-depth analysis was needed to identify causes of such distortions in the service delivery system and ways to correct it as well as using the most updated EDHS surveys to analyze trends and changes in consumer's behavior as Egypt scales up its new health insurance system.

\section{Conflicts of Interest}

The author declares no conflicts of interest regarding the publication of this paper.

\section{References}

[1] Speizer, I., et al. (2000) Do Service Providers in Tanzania Unnecessarily Restrict Clients' Access to Contraceptive Methods? International Family Planning Perspectives, 26, 13-20 + 42. https://doi.org/10.2307/2648285

[2] Stanback, J. and Twum-Baah, K. (2001) Why Do Family Planning Providers Restrict Access to Services? An Examination in Ghana. International Family Planning Pers- 
pectives, 27, 37-41. https://doi.org/10.2307/2673804

[3] Landry, D. and Forrest, J. (1996) Private Physicians' Provision of Contraceptive Services. Family Planning Perspectives, 28, 203-209.

https://doi.org/10.2307/2135839

[4] Akin, J. and Rous, J. (1997) Effect of Provider Characteristics on Choice of Contraceptive Behavior: A Two-Equation Full-Information Maximum-Likelihood Estimation. Demography, 34, 513-523. https://doi.org/10.2307/3038306

[5] Schuler, S., Bates, L. and Islam, M. (2001) The Persistence of a Service Delivery "Culture": Findings from a Qualitative Study in Bangladesh. International Family Planning Perspectives, 27, 194-200. https://doi.org/10.2307/2673855

[6] Kim, Y., et al. (2000) Self-Assessment and Peer Review: Improving Indonesian Service Providers' Communication with Clients. International Family Planning Perspectives, 26, 4-12. https://doi.org/10.2307/2648283

[7] Mayhew, S., et al. (2000) Implementing the Integration of Component Services for Reproductive Health. Studies in Family Planning, 31, 151-162.

https://doi.org/10.1111/j.1728-4465.2000.00151.x

[8] Frost, J. (2001) Public or Private Providers? U.S. Women's Use of Reproductive Health Services. Family Planning Perspectives, 33, 4-12. https://doi.org/10.2307/2673736

[9] El-Zanaty, F. and Way, A. (2001) Egypt Demographic and Health Survey 2000. Calverton, Maryland, USA; Ministry of Health and Population, Egypt; National Population Council and ORC, Macro.

[10] Heilman, E. and Martinkowsky, M. (1993) Trends in the Costs of the Family Planning Program in Egypt, Cairo, Egypt: National Population Council, Special Report Prepared under the OPTIONS II Project, 1993. 